\title{
Concentrations of Perfluorooctane Sulfonate (PFOS) and Perfluorooctanoate (PFOA) and Their Associations with Human Semen Quality Measurements
}

\author{
James H. Raymer ${ }^{1}$, Larry C. Michael ${ }^{1}$, William B. Studabaker ${ }^{1}$, Geary W. Olsen ${ }^{2}$, Carol S. \\ Sloan ${ }^{1}$, Timothy Wilcosky ${ }^{3}$, and David K. Walmer ${ }^{4}$ \\ James H. Raymer: jraymer@rti.org; Geary W. Olsen: gwolsen@mmm.com; Timothy Wilcosky: wilcosky@email.unc.edu; \\ David K. Walmer: david.walmer@duke.edu \\ ${ }^{1}$ RTI International, 3040 Cornwallis Road, P.O. Box 12194, Research Triangle Park, NC 27709 \\ 23M Company, Occupational Medicine, Mail Stop 220-06-W-08, St. Paul, MN 55144 \\ ${ }^{3}$ University of North Carolina at Chapel Hill, Epidemiology, Chapel Hill, NC 27599 \\ ${ }^{4}$ Duke University Medical Center; Medical Director, Duke Fertility Center, 5704 Fayetteville Road \\ Durham, NC 27713
}

\begin{abstract}
A total of 256 men were studied to evaluate whether serum concentrations of perfluorooctanoate (PFOA) and perfluorooctane sulfonate (PFOS) impacted semen quality or reproductive hormones. Blood and semen were collected and analyzed for perfluorochemicals and reproductive and thyroid hormones. Semen quality was assessed using standard clinical methods. Linear and logistic modeling was performed with semen profile measurements as outcomes and PFOS and PFOA in semen and plasma as explanatory variables. Adjusting for age, abstinence, and tobacco use, there was no indication that PFOA or PFOS was significantly associated with volume, sperm concentration, percent motility, swim-up motility and concentration, and directional motility (a function of motility and modal progression.) Follicle stimulating hormone was not associated with either PFOA or PFOS. Luteinizing hormone was positively correlated with plasma PFOA and PFOS, but not semen PFOS. Important methodological concerns included the lack of multiple hormonal measurements necessary to address circadian rhythms.
\end{abstract}

\section{Keywords}

Perfluorinated chemicals; PFOS; PFOA; semen quality; plasma; hormones

\section{INTRODUCTION}

Perfluoroalkyls (PFAs) are carboxylates and sulfonates of various carbon-chain lengths that have been found to be present in the environment as the result of direct and indirect sources of exposure [1-3]. The most prevalent PFAs include perfluorooctanoate (PFOA), which is

\footnotetext{
(C) 2011 Elsevier Inc. All rights reserved.

Corresponding author: James H. Raymer, RTI International, 3040 Cornwallis Road, Research Triangle Park, NC 27709, Phone: 919-541-5924, Fax: 919-316-3567, jraymer@rti.org.

Publisher's Disclaimer: This is a PDF file of an unedited manuscript that has been accepted for publication. As a service to our customers we are providing this early version of the manuscript. The manuscript will undergo copyediting, typesetting, and review of the resulting proof before it is published in its final citable form. Please note that during the production process errors may be discovered which could affect the content, and all legal disclaimers that apply to the journal pertain.
} 
used as a processing aid in the manufacture of fluoropolymers, and perfluorooctane sulfonate (PFOS), which is produced for the manufacture of surfactants, paper and packaging treatments, and surface protectants. The widespread environmental presence of PFOA and PFOS led a major manufacturer, 3M Company, to phase out production of its perfluorooctanyl chemistry. Additional regulatory exposure-reduction control measures from the U.S. Environmental Protection Agency have led the fluoropolymers industry to work toward phasing out PFOA by 2015 [4]. Recent reports of declining concentrations of PFOS and, to a lesser extent, PFOA in the general populations of the United States and Norway suggest that some of these measures may have been effective [5-8].

In conjunction with the heightened awareness of PFOA and PFOS in the environment, numerous toxicological and epidemiological research studies have been published, including several investigations of developmental outcomes in rodents, as reviewed by Lau et al. [9]. Effects, including neonatal mortality and decreased pup weight gain, have been observed with blood concentrations orders of magnitude higher than those measured in the general human population $[9,10]$.

Recently, Joensen et al. [11] conducted a cross-sectional analysis of frozen $\left(-20^{\circ} \mathrm{C}\right)$, archived (5 years) serum samples collected from 105 Danish male military recruits at their initial physical examination and measured the concentrations of nine PFAs, including PFOA and PFOS, and several sex hormones. The researchers also evaluated semen parameters that were originally measured at the date of examination. Upon summing the quartile category scores for PFOS and PFOA into low, moderate, and high, Joensen et al. reported a statistically significant difference in the median number of normal spermatozoa between the low (15.5 million) and high (6.2 million) exposure groups, as well as in the percentage of morphologically normal sperm (8.8 versus 6.3\%). All PFOA and PFOS regression coefficients were non-significantly negatively related with semen volume, sperm concentration, count, motility, and morphology. Joensen et al. concluded that PFOS and PFOA exposure may contribute to unexplained low semen quality observed in the general population, but cautioned that their results were preliminary.

The consistent findings of developmental effects in animal studies in the absence of toxicological evidence of reproductive effects attributable to PFOS and PFOA pertaining to mating or semen quality [12-14] was the initial motivation for this study, especially in the absence of non-occupational human data. The subsequent epidemiologic study published by Joensen et al. that suggested an inverse association between PFOA and PFOS with male semen quality heightened our interest in studying the biological effects PFOA and PFOS exposures at environmental concentrations. This paper summarizes the findings from a study of 256 men from the Durham, NC, area. These men presented with their partners to the Duke Fertility Center (henceforth referred to as the In vitro Fertilization [IVF] Clinic) at Duke University Medical Center for an assessment. Our study's primary purpose was to determine whether plasma and semen concentrations of PFOS and PFOA were associated with semen quality and reproductive hormones.

\section{METHODS}

\subsection{Study Design/Objectives}

This was a cross-sectional study conducted between 2002 and 2005 in the Durham, NC, area in collaboration with Duke University Medical Center's IVF Clinic. If any exposure effects are limited to a sensitive subset of the general population, this study population may be more likely to reveal an association than a study that samples the general population. Samples of blood and semen were collected and analyzed for PFOS and PFOA; concentrations in these 
biological matrices, especially blood, reflect multi-route exposures. These men were anticipated to represent a range of general population exposures to these PFAs.

\subsection{Sample and Data Collection}

All data collection protocols and informed consent were approved by the Institutional Review Boards at both RTI International (RTI) and Duke University Medical Center. Duke University Medical Center's IVF Clinic recruited a total of 256 men to participate in this study between 2002 and 2005.

Blood and semen samples were collected at the time of evaluation and stored in polypropylene containers prior to analyses. Aliquots of plasma and semen were placed into polypropylene cryotubes, stored at $-20^{\circ} \mathrm{C}$, and transported to RTI for analysis of hormones, PFOS, and PFOA. Reproductive health questionnaires were administered that inquired about medical history and sexual activity, including duration of abstinence prior to sample collection.

\subsection{Sample Analysis}

2.3.1 Semen Analysis-Both routine semen measures (e.g., viscosity, volume, $\mathrm{pH}$, sperm concentration, white blood cell concentration) and tests of functional motility (e.g., 30 minute swim-up test) were assessed in the College of American Pathologists accredited andrology laboratory at Duke University. The 30-minute swim-up total motile count was included in our analysis because it is used clinically at the IVF Clinic at Duke University Medical Center to determine which infertile couples should consider using intracytoplasmic sperm injection to assist with fertilization. An internal quality improvement exercise at the IVF Clinic at Duke University Medical Center revealed that a 30-minute swim-up count of less than 1 million sperm $/ \mathrm{mL}$, or less than 100,000 sperm $/ \mathrm{mL}$, correlated with a risk of poor fertilization (i.e., less than $20 \%$ of oocytes) of $15 \%$ and $85 \%$, respectively, following natural insemination (Walmer, D., unpublished data).

Semen samples were obtained within 7 days of the last ejaculation, but after a minimum 48hour abstinence timeframe. Upon collection of the semen sample into a sterile specimen cup, the sample was delivered to the laboratory within 1 hour. If an off-site sample was delivered to the laboratory that was greater than 1 hour old and the motility of the spermatozoa was less than $25 \%$, then the patient was rescheduled. While en route to the laboratory, the samples were not exposed to temperature extremes (not less than $25^{\circ} \mathrm{C}$ and not greater than $40^{\circ} \mathrm{C}$ ). Motility assessment was performed using a Cell-Vu counting chamber within a 35$37^{\circ} \mathrm{C}$ temperature range. The concentration of spermatozoa in the semen was determined by using an improved Neubauer hemacytometer using the following serial dilutions: no dilution, 1:10, and 1:100 in distilled water. Each parameter (motility and concentration) was measured in duplicate, and the assessments must have been within $10 \%$ of each other.

Briefly, the swim-up assay was prepared by pipetting one-quarter of the semen volume into two $15-\mathrm{mL}$ centrifuge tubes for swim-up preparation. A total of $5 \mathrm{~mL}$ of insemination medium was added to each tube and thoroughly mixed for 10 minutes. After centrifuging, the supernatant was aspirated and discarded from both tubes. Two milliliters of insemination media were then added to one of the tubes, and the pellet was resuspended. The suspension was then transferred to the second tube, and the pellet was resuspended with subsequent centrifuging at $200 \times \mathrm{g}$ for 10 minutes. The supernatant was discarded, and then $2.5 \mathrm{~mL}$ of insemination medium were added to overlay the pellet. The tube was then incubated for 30 minutes at $37^{\circ} \mathrm{C}$ and $5 \%$ carbon dioxide in room air with subsequent careful transfer of the top $1 \mathrm{~mL}$ of overlay to a clean $15-\mathrm{mL}$ centrifuge tube for determination of concentration and motility of the swim-up fraction. Forward linear progress was estimated as spermatozoon 
moving within 45 degrees to either side in the direction the head is pointing at a rate of at least two head lengths per second.

2.3.2 Categorical Variables for Regression-Frequency distributions for the six categorical semen profile measurements (i.e., liquefaction, viscosity, volume, sperm concentration, modal progression, and swim-up overnight progression) analyzed as normal or abnormal suggested that the males in this study were more typical of fertile males (Table 1). Dichotomous variables reflecting normal and abnormal were created from the continuous measurements for three of these parameters (i.e., volume, sperm concentration, and swim-up overnight motility) based on reference values in the World Health Organization's Laboratory Manual for the Examination and Processing of Human Semen [15] or IVF laboratory practices as follows:

- Liquifaction:

- Normal: Liquified by 60 minutes at room temperature

- Abnormal: Not liquified by 60 minutes at room temperature

- "Liquefied" is defined as the ability to draw the sample into a pipette

- Viscosity:

- Normal: Pipetable

- Abnormal: Not pipetable

- Volume:

- Normal: $\geq 1.5 \mathrm{~mL}$ [15]

- Abnormal: $<1.5 \mathrm{~mL}$

- Sperm Concentration:

- Normal: $\geq 15 \times 10^{6} / \mathrm{mL}$ [15]

- Abnormal: $<15 \times 10^{6} / \mathrm{mL}$

- Modal Progression:

- $\quad$ Normal: $>50 \%$ of the motile sperm made definite forward linear progress

- Abnormal: $>50 \%$ of the motile sperm made weak or no forward progress

- $\quad$ Swim-Up Overnight Motility [15]:

- Normal: $\geq 28 \%$

- Abnormal: $<28 \%$.

2.3.3 Hormone Analysis-Hormone analyses were conducted at RTI. Total and free testosterone, follicle-stimulating hormone (FSH), luteinizing hormone $(\mathrm{LH})$, prolactin, triiodothyronine (T3), and thyroxine (T4) assay kits were purchased from Diagnostic Products Corporation (now Siemens Healthcare Diagnostics, Deerfield, IL) and were validated in human samples prior to use on the study samples. Estradiol and thyroidstimulating hormone (TSH) assay kits were purchased from Diagnostic Systems Laboratories (now Beckman Coulter, Webster, TX).

2.3.4 Chemical Analysis-Representative samples of all supplies that would contact blood, semen, or their extracts were screened for PFOS or PFOA by rinsing with methanol and analyzing the extract by high-performance liquid chromatography with tandem mass 
spectrometry (HPLC-MS/MS) as subsequently described. Extracts containing PFOS or PFOA above instrument background resulted in the rejection of those specific supply lots.

All perfluorinated standards were purchased from Sigma-Aldrich (St. Louis, MO). At the time when the analytical method was set up, fully characterized, isotopically labeled standards were not available to us, so the non-labeled homologs perfluorodecanoic acid (PFDA) and perfluorododecanoic acid (PFDoA) were used as surrogate recovery and quantitation standards, respectively. PFDA, as received, contained $0.6 \%$ of PFOA. At the spiking concentration used $(5 \mathrm{ng} / \mathrm{mL}$ in the sample), this would contribute to $<5 \%$ of the lower limit of quantification; nevertheless, the PFDA was further purified by preparative HPLC (see Supplementary Information) to give a single peak ( $<0.1 \%$ of PFOA) by HPLCMS/MS. Semen samples were thawed, and $0.5 \mathrm{~mL}$ was transferred to a polypropylene tube; $5 \mu \mathrm{L}$ of a PFDA solution $(500 \mu \mathrm{g} / \mathrm{mL})$ and $0.5 \mathrm{~mL}$ of a $1.4 \%$ phosphoric acid solution were added, and the sample was vortexed. Solid-phase extraction columns (Oasis WAX, $6 \mathrm{cc}$, Waters Corporation, Milford, MA) were preconditioned with $3 \mathrm{~mL}$ of methanol and then 3 $\mathrm{mL}$ of water. Samples were loaded, and columns were washed with $4 \mathrm{~mL}$ of $25 \mathrm{mM}$ acetate buffer, $\mathrm{pH} 5.0$, followed by $4 \mathrm{~mL}$ of methanol. The columns were eluted with $4 \mathrm{~mL}$ of 20/80 methanol/acetonitrile (v/v) $+2 \%$ of ammonium hydroxide. The solvent was evaporated at $45^{\circ} \mathrm{C}$ under a stream of nitrogen, and the residue was reconstituted in $500 \mu \mathrm{L}$ of methanol, spiked with $50 \mu \mathrm{L}$ of quantitation standard solution (PFDoA at $135 \mathrm{ng} / \mathrm{mL}$ ), and transferred to an autosampler vial. The same method was used to prepare the plasma samples, except that 3-cc Oasis WAX columns were used, and column washing and eluent volumes were accordingly reduced by half.

Extracts were analyzed on a PE-Sciex API-3000 HPLC-MS/MS Vernon Hills, IL) system using negative electrospray ionization, with data acquired in the multiple reaction monitoring mode. Separation was accomplished using a Betasil C18, $100 \times 2.0-\mathrm{mm}, 5-\mu \mathrm{m}$ particle LC column (Thermo Fisher Scientific, Waltham, MA) with the following gradient program: mobile phase "A" $=5 \%$ methanol: $95 \%, 2 \mathrm{mM}$ ammonium acetate in water; mobile phase "B" $=95 \%$ methanol: $5 \%, 2 \mathrm{mM}$ ammonium acetate in water. The mobile phase was initially held at $50 \%$ B for 5 minutes, followed by a linear gradient to $100 \%$ B over 20 minutes and returned to 50\% B in 1 minute with a 10-minute hold for column reequilibration. Data were acquired using PE-Sciex Analyst 1.1 software under Microsoft Windows NT 4.0. Calibration was carried out using solutions containing PFOS and PFOA concentrations ranging from 0.1 to $100 \mathrm{ng} / \mathrm{mL}$.

\subsubsection{Quality Assurance/Quality Control}

Quality Control: To characterize method performance and define the quality of the data, field blanks, field controls, laboratory method blanks, and laboratory method control samples were prepared and analyzed throughout the study, along with samples from study participants. During instrumental analysis, a calibration check standard was analyzed every 10 samples to verify stability of the instrument calibration. Calibration was considered stable if the deviation of the calculated check standard concentration was less than $\pm 15 \%$ of nominal. In addition, 16 samples of both semen and plasma were extracted and analyzed in duplicate to characterize method precision. Duplicate samples were averaged for data analysis. Instrumental analysis precision was characterized by analyzing a subset of sample extracts in duplicate.

Quality Assurance: Analytical performance was further explored to demonstrate that our method utilized from 2002 to 2005 yielded results comparable to those obtained using current analytical methods employing istopically labeled internal standards. Therefore, an interlaboratory comparison was performed whereby 30 plasma samples that had been 
analyzed at RTI prior to 2005 were transferred in 2008 to 3M Company's Strategic Toxicology Laboratory (St. Paul, MN) for independent determination of PFOS and PFOA by HPLC-MS/MS using isotopically labeled internal standards. Concentration data from each laboratory were compared by paired $t$-tests with cognizance of variance in homogeneity.

\subsection{Statistical Analysis}

Data from questionnaires, semen profile measurements, and the chemical analyses of PFOS and PFOA in semen and plasma were assembled into SAS (v.9.2) data sets and evaluated for comparability between the original data and analysis-level data sets. Exact agreement was confirmed for the number of measurements for PFOS, PFOA, semen profile characteristics, and hormones in each matrix against the number of samples collected and analyzed. Summary distributions for all measurements were examined for the presence of unusual values; all extreme values were confirmed against the raw laboratory data. Lastly, accuracy of data import into SAS was confirmed by confirmation of at least $10 \%$ of all measurements against the original data.

Summary statistics for continuous variables (i.e., semen profile and perfluorooctyl measurements) and categorical variables (i.e., questionnaire responses) were generated by univariate and frequency analyses, respectively, on the complete data sets. Assessment of distributional assumptions for the continuous outcome variables revealed no significant difference in model fit for logged or unlogged outcomes; therefore, only unlogged outcomes were modeled for both semen and plasma. Both logistic and linear modeling efforts were performed using unlogged PFA explanatory variables in a three-phased approach:

1. A sub-model with PFOS and PFOA alone as explanatory variables, without correction for age, duration of abstinence, or tobacco use (primarily smoking)

2. A full model with PFOS, PFOA, age duration of abstinence, and tobacco use

3. A forward selection model with PFOS and PFOA required admitting age, duration of abstinence, and tobacco only when their significance in the model was within an alpha of 0.5 .

Odds ratios were computed for categorical outcomes by modeling against the most favorable outcome (e.g., normal modal progression).

All measurements for two participants were excluded based on a white blood cell count of $17 \times 10^{5} / \mathrm{mL}$ for one participant and a duration of abstinence of 30 days for another. These extreme values were not representative and accounted for less than $1 \%$ of our study population. All significance levels for the linear and logistic regression models were reported.

\section{RESULTS}

\subsection{Method Performance}

\subsubsection{Quality Control}

Duplicates: Replicate extraction and analysis of 21 pairs of plasma samples yielded coefficients of variation (CVs) of $22 \%$ for PFOA and $16 \%$ for PFOS. Replicate analysis of 17 semen samples yielded a CV of $21 \%$ for PFOS; PFOA semen concentrations were too low to yield useful precision data. Duplicate instrumental analysis yielded CVs of 3 to $18 \%$ across analytes and matrices. 
Surrogate Recovery: Mean surrogate (PFDA) recoveries from plasma and semen quality control samples and study samples are summarized in Table 2 . In general, recovery of the surrogate was consistent across matrices and sample types.

Controls: Recoveries from laboratory method controls are summarized in Table 3. Analyte recoveries from three field plasma controls were 68 to $87 \%$ for PFOS, and 109 to $148 \%$ for PFOA, consistent with ranges from method controls. Recoveries from five field semen controls were 61 to $87 \%$ for PFOS, and 66 to $86 \%$ for PFOA, also consistent with the method controls.

Blanks: Perfluorocarbon-based fittings and solvent transfer lines on the HPLC contributed to a background PFOA signal that was kept at acceptable levels by system flushing. Before analysis of any sample batch, a system blank was assessed to ensure that the background contribution of PFOA was less than $20 \%$ of the lowest calibration standard. If the PFOA background concentrations were found to be excessive, the system was flushed with $50 \mathrm{~mL}$ of mobile phase, and the new blank was analyzed. Using PFOA measurements in laboratory method blanks, we determined the detection limits (40 Code of Federal Regulations Part 136, Appendix B) to be $1.2 \mathrm{ng} / \mathrm{mL}$ for both semen $(\mathrm{n}=44)$ and plasma $(\mathrm{n}=27)$. The PFOS background concentration was lower and blank analyses yielded detection limits of $0.4 \mathrm{ng} /$ $\mathrm{mL}$ for both semen and plasma. Field blanks ( $\mathrm{n}=5$ for semen, $\mathrm{n}=3$ for plasma) were consistent with method blanks.

3.1.2 Quality Assurance-A comparison of the 30 plasma samples that were analyzed jointly by RTI and 3M Company, by examination of the measurement ratios, when values were surrogate-corrected and uncorrected, yielded the best agreements using PFOS uncorrected for surrogate recovery (Spearman ranked correlation of $0.752, \mathrm{p}=<0.0001$; see Figure S1). For PFOA, the best measurement agreement was for PFOA corrected for surrogate recovery (Spearman ranked correlation of 0.305 for uncorrected; Figure S2a and 0.712, ( $<<0.0001$ ) for corrected, see Figure S2b). Paired $t$-tests (with correction for variance heterogeneity) performed on the corrected and uncorrected RTI data versus 3M Company's results showed statistically significant $(\mathrm{p}<0.0001, \mathrm{p}=0.0119)$ differences between the two measurements in all cases except the surrogate recovery-corrected PFOA results.

\subsection{Analyses}

Tables 4 through 6 provide measures of central tendency of matrix-dependent PFOS and PFOA concentrations $(\mathrm{ng} / \mathrm{mL})$ and hormones as related to factors that may influence semen quality (e.g., age, duration of abstinence, tobacco use) and the actual measurements. Of the 254 subjects whose median age and duration of abstinence was 41.0 years and 3.0 days, respectively, their median sperm concentration was $58 \times 106 / \mathrm{mL}$ (a range of 0 to $432 \times 106$ / $\mathrm{mL}$ ), with the percent motile sperm observed at 53.3\% (Table 4). Both swim-up concentration and the swim-up total motile concentration (swim-up concentration $\times$ swimup motility) had median counts of $1.5 \times 106 \mathrm{~mL}-1$. Median plasma PFOS and PFOA concentrations were $32.3 \mathrm{ng} / \mathrm{mL}$ and $5.2 \mathrm{ng} / \mathrm{mL}$, respectively (Table 5). The median semen PFOS concentration was $0.6 \mathrm{ng} / \mathrm{mL}$. Only $2 \%$ of the semen PFOA concentrations were reported greater than the limit of quantitation. All median hormone concentrations presented in Table 6 were measured within their respective reference ranges (data not shown). Differences in the number of observations are attributable to limitations in sample quantities for semen PFA analyses, and to completeness of covariates required for modeling.

As expected, plasma PFOS and PFOA concentrations were highly correlated with each other $(\rho=0.669, p<0.0001)$, as was PFOS plasma and semen concentrations $(\rho=0.441, p$ 
$<0.0001)$. Plasma PFOA and semen PFOS concentrations were not significantly correlated $(\rho=0.107, p=0.113)$.

Provided in Table 7 are the unadjusted and adjusted regression PFOS (plasma and semen) and PFOA (plasma) coefficients, 95\% confidence intervals, and p values for 10 semen quality characteristics. There were no statistically significant unadjusted or adjusted coefficients, including those for the swim-up total motile count (swim-up count $\times$ motility $\%)$ for PFOS in plasma $\left(\beta_{\mathrm{adj}}=0.0007, \mathrm{p}=0.850\right)$, PFOS semen $\left(\beta_{\mathrm{adj}}=0.0256, \mathrm{p}=0.861\right)$, and plasma PFOA ( $\beta_{\text {adj }}=0.0085, p=0.548$ ). In addition, there were no statistically significant odds ratios observed when five semen quality characteristics were categorized as normal or abnormal (Table 8). Statistically significant correlations with hormones ( $\mathrm{p}<0.05$ ) were observed (Table 9) for the following: (1) plasma PFOS and T3, and (2) plasma PFOA with free testosterone and LH. Marginal non-significant correlations were observed with plasma PFOS and LH, as well as plasma PFOA and T4. Estradiol, total testosterone, FSH, and prolactin were not significantly correlated with PFOS plasma and semen concentrations or with plasma PFOA.

\section{DISCUSSION}

Along with their female partners, a total of 256 males presented for fertility assessments at Duke University Medical Center's IVF Clinic. In our cross-sectional analysis of these data, we did not observe semen quality to be statistically significantly (negatively) associated with either plasma or semen concentrations of PFOS, or with plasma PFOA levels. Assessment of semen quality was reasonably comprehensive and included the following: volume, sperm concentration, percent motility, swim-up motility and concentration, and directional motility (a function of motility and modal progression). We could not address semen quality related to semen PFOA concentrations because less than $2 \%$ of these PFOA measurements were above the limit of quantitation. In addition to semen quality analyses, several hormones associated with spermatogenesis were measured. Among the most important hormone indicators of impaired spermatogenesis, FSH was not associated with either PFOA or PFOS; however, inhibin B was not measured [16]. LH was positively correlated with plasma PFOS and PFOA, but not with semen PFOS. There were no statistically significant correlations with total testosterone or estradiol. We have not quantitatively considered in our significance threshold $(\mathrm{p}<0.05)$ comparisons of multiple hormone indicators with multiple chemical measurements. This would result in a net reduction of the significance level by at least a factor of nine; therefore, significance between $\mathrm{p}<0.01$ and $<0.05$ must be viewed with caution.

Statistically significant correlations were observed for TSH and plasma PFOS and T3 with plasma and semen PFOS, but not plasma PFOA. In toxicological studies, the principal diagnostic indicator of serum thyroid hormone status, TSH, was unchanged in animals administered PFOS [12, 17-19]. Although, in these studies, there were reported decreases in circulating levels of free thyroid hormones, these decreases were the result of an artificial negative bias with the analog assay procedure employed. Such interference disappeared when an equilibrium dialysis reference method was used [20]. This bias does not appear to be a methodological issue with PFA measurements at the levels found in the blood of the general population [21]. In addition, there were no changes in thyroid histology; hence, there was no evidence of clinical hypothyroidism in experimental animal studies following either short-term or long-term administration of PFOS [22]. General population and occupational studies have occasionally shown various statistical associations with either thyroid hormones, with PFOS [23, 24], or with PFOA [25], but none of them have represented clinically relevant changes. 
The distributions of the PFOA and PFOS concentrations measured in our study were comparable to the time-related (2003-2004) collection data reported by the Centers for Disease Control and Prevention for the general U.S. population [5] and slightly higher than those reported by Joensen et al. [11] in their study of sperm quality in Danish military recruits. This difference could be attributed to geography and the declines in PFOS and, to a lesser extent, PFOA in the U.S. general population [5].

Both Joensen et al.'s [11] research and our study could not address temporality because of their cross-sectional designs and because they lacked the multiple hormonal measurements necessary to address hormonal circadian rhythms. Both studies measured serum PFOS and PFOA concentrations similar to those observed in the general population $[5,6]$.

Nevertheless, the two studies reported different associations regarding semen quality. Joensen et al. observed a $60 \%(\mathrm{p}<0.03)$ decline in median normal spermatozoa between their study subjects defined as having high versus low combined serum PFOS and PFOA concentrations. There was essentially no indication that PFOS or PFOA was associated with any semen quality parameter in our study. We cannot offer any substantive reasons for the different findings in semen quality between the two studies, despite similar general population-level PFOS and PFOA concentrations. The one substantive difference is the older age of our study population. No studies published in the literature have assessed semen quality of highly exposed workers involved in the manufacture of PFAs. Occupational epidemiologic studies [26-28] have shown inconsistent associations between serum concentrations of PFOA (measured to be two to three orders of magnitude higher than the general population) and estradiol and testosterone. Measurements of FSH and LH were not associated with PFOA in the only occupational setting that reported this analysis [27].

There are two studies that examined male reproductive toxicity data in rats exposed to PFOS or PFOA [12-14]. Luebker et al. [12] conducted a two-generation reproduction study of PFOS in $\mathrm{CD}^{\circledR}$ rats. Male rats were administered (by gavage) $0.0,0.1,0.4,1.6$, and $3.2 \mathrm{mg} /$ $\mathrm{kg}$-day of potassium PFOS beginning 42 days prior to mating and through the mating period. Although no specific semen parameters were reported, mating and fertility parameters were not adversely affected for any dose group. Fertility indices (i.e., the number of pregnancies per the number of rats that mated) for male rats were 94.3, 91.4, 81.8, 85.0, and $87.5 \%$ for the control and four dose groups, respectively. Fertility indices for female rats were $94.3,91.4,82.4,85.3$, and $85.7 \%$, respectively. All females were successfully mated except for one rat in the $0.4 \mathrm{mg} / \mathrm{kg}$-day group.

In a two-generation reproduction study of PFOA administered to rats at $0,1,3,10$, and 30 $\mathrm{mg} / \mathrm{kg}$-day, Butenhoff et al. [13] reported that there was normal fertility and sperm parameters, without providing specifics. Detailed analyses were subsequently provided by York et al. [14] who reported cauda epididymal sperm motility, count, and density, and spermatid count and density in both the P- and F1-generation male rats across these dose groups. No statistically significant trends were observed except for static count in the Pgeneration male rats. Based on historic control data of the laboratory, this trend was attributed to a higher static count in the control rats rather than the lower comparable counts in the four dosed groups. No significant trends in abnormal morphology were reported in either the P- or F1-generation male rats.

In another study, Biegel et al. [29] reported an increase in estradiol levels from PFOAtreated rats. This increase was primarily due to aromatase induction in the liver. Data from a sub-chronic rodent study also suggested the same outcome [30]. Estradiol and testosterone measurements were measured in male and female monkeys administered (by gavage) doses of potassium PFOS at $0,0.03,0.15$, and $0.75 \mathrm{mg} / \mathrm{kg}$-day [17]. Lowered estradiol values were reported in both male and female monkeys in the $0.75 \mathrm{mg} / \mathrm{kg}$-day dose group. This outcome 
was not observed for testosterone. As previously discussed, estradiol levels were not significantly associated with increased PFOA concentrations in our study.

A potential limitation in the measurements in our study was the unavailability of isotopically labeled standards for the analysis of plasma and semen samples for PFOS and PFOA. In additional to an interlaboratory study in which the RTI method for the determination of PFA compounds in plasma was found to perform comparably to techniques used by other laboratories [31], method suitability was assessed by the analysis of a subset of 30 samples from the current study at 3M Company's laboratory Although the plasma measurements made at the two laboratories are similar, only RTI's recovery-corrected PFOA results compare quantitatively to the results obtained for this analyte at 3M Company's laboratory. The improvement in agreement and correlation of RTI's data with 3M Company's data on application of a surrogate recovery, as illustrated in Figure S2a and b, are consistent with the expected behavior during sample preparation associated with chemically similar PFDA (surrogate) and PFOA. Carboxylic and sulfonic acids may be reasonably expected to behave more dissimilarly during sample preparation, and it is not surprising that correction of RTI's PFOS data using PFDA recoveries did not improve agreement with 3M Company's data. That the paired $t$-tests for the uncorrected PFOS concentrations indicated a difference between the two laboratories is a function of the high correlation between most of the sample values; if a single outlier evident at the top left of Figure S1 is excluded from both analyses, the bias in both data sets is identical. Our conclusion regarding the comparison between the two laboratories is that although different results were found, because different methodologies were used, the highly significant correlations between RTI's and 3M Company's measurements for a given chemical species, even for surrogate-unadjusted values, strongly suggests that these differences do not materially affect the results of this study.

\section{CONCLUSIONS}

Our study participants were selected because they were presumed to represent both fertile and infertile populations. If PFOA or PFOS adversely affected spermatogenesis, our working hypothesis was that the association may be more readily detected in an infertile male population. Of the 256 men evaluated at Duke University Medical Center's IVF Clinic as part of an assessment of infertility among couples, PFOS and PFOA were measureable in $90 \%$ of the plasma and $59 \%$ and $2 \%$, respectively, of the semen samples, with a median value of PFOS in serum four to five times higher than that for PFOA. Plasma concentrations were similar to those reported in time-dependent general population studies. Concentrations in semen were nearly an order of magnitude lower than those measured in plasma. Plasma PFOS was highly correlated with semen PFOS concentrations, but this could not be determined for PFOA, owing to the few semen measurements exceeding the instrumental detection limit.

There was no indication that PFOS or PFOA were significantly associated with any semen quality parameter. Assessment of semen quality included the following: volume, sperm concentration, percent motility, swim-up motility and concentration, and directional motility (a function of motility and modal progression). Among the most important hormone indicators of impaired spermatogenesis, FSH was not associated with either PFOA or PFOS, and LH was positively correlated with plasma PFOS and PFOA, but not with semen PFOS. Because of our study's cross-sectional design, important methodological issues pertaining to hormonal analyses could not be addressed, including the need for multiple measurements to adequately address circadian variations in hormone concentrations. 


\section{Supplementary Material}

Refer to Web version on PubMed Central for supplementary material.

\section{Acknowledgments}

This work was supported by a National Institutes of Environmental Health Sciences Grant 5R01ES11683-3 and 3M Company. Thanks to Michelle McCombs and Michael Gardner (field activities, chemical analyses) and Susan Pearce (hormone analyses) of RTI; Jennifer Mangum and Ann Wade (participant recruitment, sample collection) of the IVF Clinic at Duke University Medical Center; and Dave Ehresman (quality assurance chemical analysis, valuable discussions, draft manuscript review) of 3M Company for their support during this study.

\section{References}

1. Paul AG, Jones KC, Sweetman AJ. A first global production, emission, and environmental inventory for perfluorooctane sulfonate. Environ Sci Technol. 2009; 43:386-92. [PubMed: 19238969]

2. Prevedouros K, Cousins IT, Buck RC, Korzeniowski SH. Sources, fate and transport of perfluorocarboxylates. Environ Sci Technol. 2006; 40:32-43. [PubMed: 16433330]

3. Trudel D, Horowitz L, Wormuth M, Scheringer M, Cousins IT, Hungerbűhler K. Estimating consumer exposure to PFOS and PFOA. Risk Anal. 2008; 28:251-69. [PubMed: 18419647]

4. U.S. EPA (Environmental Protection Agency). [Accessed December 16, 2010] 2010/2015 PFOA Stewardship Program Homepage. 2010. Available from: http://www.epa.gov/oppt/pfoa/pubs/stewardship/index.html

5. Kato K, Wong LY, Lily T, Zsuzsanna K, Calafat AM. Trends in exposure to polyfluoroalkyl chemicals in the U.S. population: 1999-2008. Environ Sci Technol. doi:dx.doi.org/10.1021/ es1043613.

6. Haug LS, Thomsen C, Becher G. Time trends and the influence of age and gender on serum concentrations of perfluorinated compounds in archived human samples. Environ Sci Technol. 2009 Mar 15; 43(6):2131-6. [PubMed: 19368225]

7. Olsen GW, Mair DC, Church TR, Ellefson ME, Reagen WK, Boyd TM, et al. Decline in perfluorooctanesulfonate and other polyfluoroalkyl chemicals in American Red Cross adult blood donors, 2000-2006. Environ Sci Technol. 2008; 42:4989-95. [PubMed: 18678038]

8. Spliethoff HM, Tao L, Shaver SM, Aldous KM, Pass KA, Kannan K, et al. Use of newborn screening program blood spots for exposure assessment: Declining levels of perfluorinated compounds in New York State infants. Environ Sci Technol. 2008; 42:5361-7. [PubMed: 18754394]

9. Lau C, Anitole K, Hodes C, Lai D, Pfahles-Hutchens A, Seed J. Perfluoroalkyl acids: A review of monitoring and toxicological findings. Toxicol Sci. 2007; 99:366-94. [PubMed: 17519394]

10. Olsen GW, Butenhoff JL, Zobel LR. Perfluoroalkyl chemicals and human fetal development: An epidemiologic review with clinical and toxicological perspectives. Reprod Toxicol. 2009; 27:21230. [PubMed: 19429401]

11. Joensen UN, Bossi R, Leffers H, Jensen AA, Skakkebaek NE. Do perfluoroalkyl compounds impact human semen quality? Environ Health Perspect. 2009; 117:923-7. [PubMed: 19590684]

12. Luebker DJ, Case MT, York RG, Moore JA, Hansen KJ, Butenhoff JL. Two-generation reproduction and cross-foster studies of perfluorooctanesulfonate (PFOS) in rats. Toxicology. 2005; 215:126-48. [PubMed: 16146667]

13. Butenhoff JL, Kennedy GL, Frame SR, O'Connor JC, York RG. The reproductive toxicology of ammonium perfluorooctanoate (APFO) in the rat. Toxicology. 2004; 196:95-116. [PubMed: 15036760]

14. York RG, Kennedy GL, Olsen GW, Butenhoff JL. Male reproductive system parameters in a twogeneration reproduction study of ammonium perfluorooctanoate in rats and human relevance. Toxicology. 2010; 271:64-72. [PubMed: 20223269]

15. World Health Organization. WHO laboratory manual for the examination and processing of human semen. 5. World Health Organization Press; Geneva, Switzerland: 2010. 
16. Meachem SJ, Nieschlage E, Simoni M. Inhibin B in male reproduction: pathophysiology and clinical relevance. Eur J Endocrinol. 2001; 145:561-71. [PubMed: 11720872]

17. Seacat AM, Thomford PJ, Hasne KJ, Olsen GW, Case MT, Butenhoff JL. Subchronic toxicity studies on perfluorooctanesulfonate potassium salt in cynomolgus monkeys. Toxicol Sci. 2002; 68:249-64. [PubMed: 12075127]

18. Thibodeaux JR, Hanson RG, Rogers JM, Grey BE, Barbee BD, Richards JH, et al. Exposure to perfluorooctane sulfonate during pregnancy in rat and mouse. I: Maternal and prenatal evaluations. Toxicol Sci. 2003; 74:369-81. [PubMed: 12773773]

19. Lau C, Thibodeaux JR, Hanson RG, Rogers JM, Grey BE, Stanton ME, et al. Exposureto perfluorooctane sulfonate during pregnancy in rat and mouse. II: postnatal evaluation. Toxicol Sci. 2003; 74:382-92. [PubMed: 12773772]

20. Chang SC, Thibodeaux JR, Eastvold ML, Ehresman DJ, Bjork JA, Froehlich JW, et al. Negative bias from analog methods used in the analysis of free thyroxine in rat serum containing perfluorocotanesulfoante (PFOS). Toxicology. 2007; 234:21-33. [PubMed: 17368689]

21. Lopez-Espinosa MJ, Fitz-Simon N, Bloom MS, Clafat AM, Fletcher T. Comparison between free serum thyroxine levels, measured by analog and dialysis methods, in the presence of perfluorooctane sulfoante and perfluoroctanoate. Repro Toxicol. 10.1016/j.reprotox.2011.04.002

22. Chang SC, Thibodeaux JR, Eastvold ML, Ehresman DJ, Bjork JA, Froehlich JW, et al. Thyroid hormone status and pituitary function in adult rats given oral doses of perfluorooctanesulfonate (PFOS). Toxicology. 2008; 243:330-9. [PubMed: 18063289]

23. Dallaire R, Dewailly E, Pereg D, Dery S, Ayotte P. Thyroid function and plasma concentrations of polyhalogenated compounds in Inuit adults. Environ Health Perspect. 2009 Sep; 117(9):1380-6. [PubMed: 19750101]

24. Olsen GW, Burris JM, Burlew MM, Mandel JH. Epidemiologic assessment of worker serum perfluoroctanesulfonate (PFOS) and perfluorooctanoate (PFOA) concentrations and medical surveillance examinations. J Occup Environ Med. 2003; 45:260-70. [PubMed: 12661183]

25. Olsen GW, Zobel LR. Assessment of lipid, hepatic, and thyroid parameters with serum perfluorooctanoate (PFOA) concentrations in fluorochemical production workers. Int Arch Occup Environ Health. 2007; 81:231-46. [PubMed: 17605032]

26. Costa G, Sartori S, Consonni D. Thirty years of medical surveillance in perfluorooctanoic acid production workers. J Occup Environ Med. 2009; 51:364-72. [PubMed: 19225424]

27. Olsen GW, Gilliland FD, Burlew MM, Burris MPH, Jean M, Mandel JS, et al. An epidemiologic investigation of reproductive hormones in men with occupational exposure to perfluorooctanoic acid. J Occup Environ Med. 1998; 40:614-22. [PubMed: 9675720]

28. Sakr CJ, Kreckman KH, Green JW, Gillies PJ, Reynolds JL, Leonard RC. Cross-sectional study of lipids and liver enzymes related to a serum biomarker of exposure (ammonium perfluorooctanoate or APFO) as part of a general health survey in a cohort of occupationally exposed workers. J Occup Environ Med. 2007; 49:1086-96. [PubMed: 18000414]

29. Biegel LB, Liu RCM, Hurtt ME, Cook JC. Effects of ammonium perfluorooctanoate on Leydig cell function: In vitro, in vivo, and ex vivo studies. Toxicol Appl Pharmacol. 1995; 134:18-25. [PubMed: 7676454]

30. Perkins RG, Butenhoff JL, Kennedy GL, Palazzol MJ. 13-Week dietary toxicity study of ammonium perfluorooctanoate (APFO) in male rats. Drug Chem Toxicol. 2004; 27:361-78. [PubMed: 15573472]

31. Longnecker MP, Smith CS, Kissling GE, Hoppin JA, Butenhoff JL, Decker E, et al. An interlaboratory study of perfluorinated alkyl compound levels in human plasma. Environ Res. 2008; 107(2):152-159. [PubMed: 18295197] 


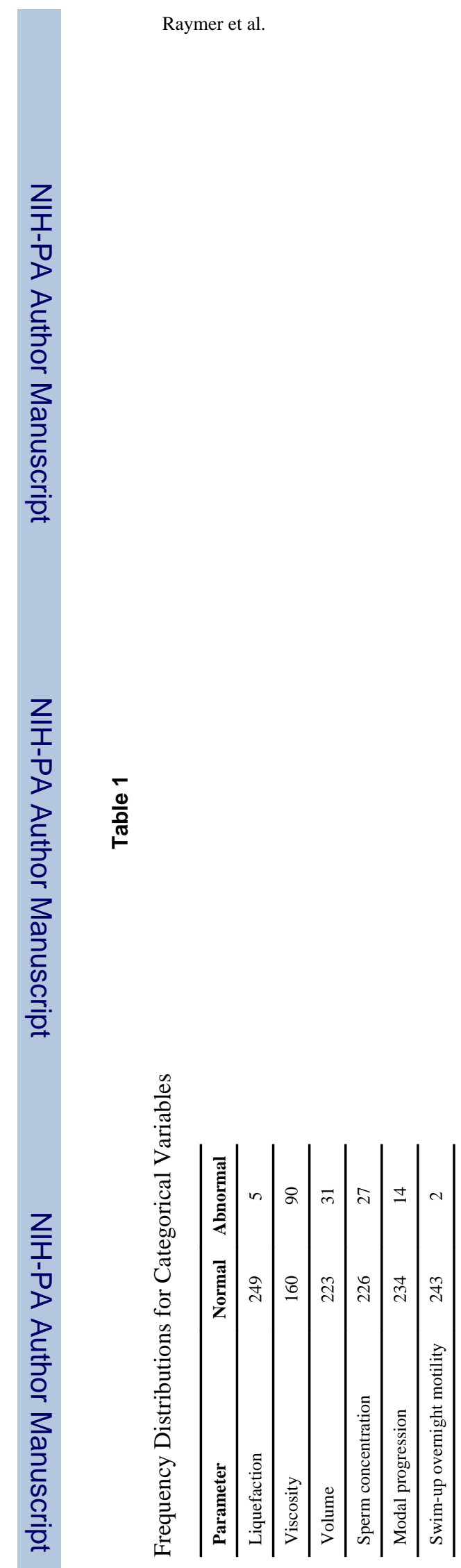

Reprod Toxicol. Author manuscript; available in PMC 2013 July 01. 


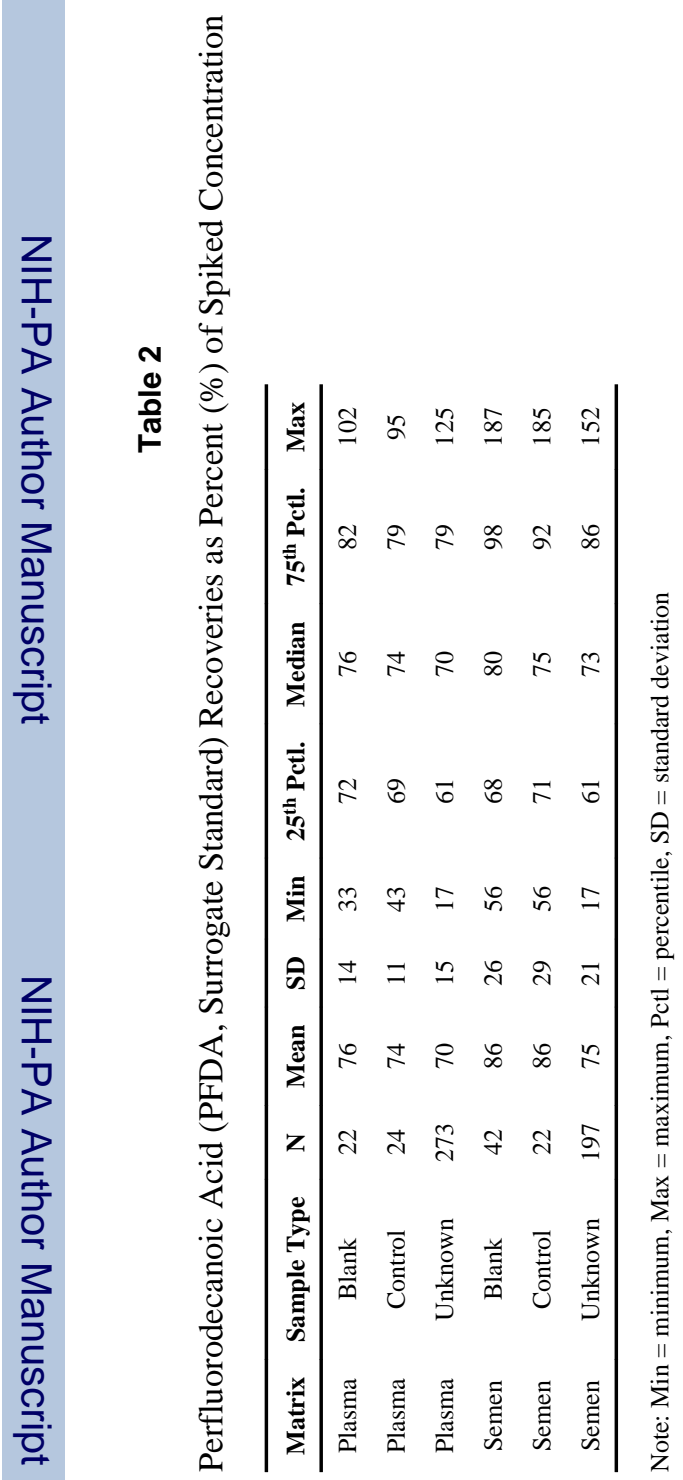

Reprod Toxicol. Author manuscript; available in PMC 2013 July 01. 


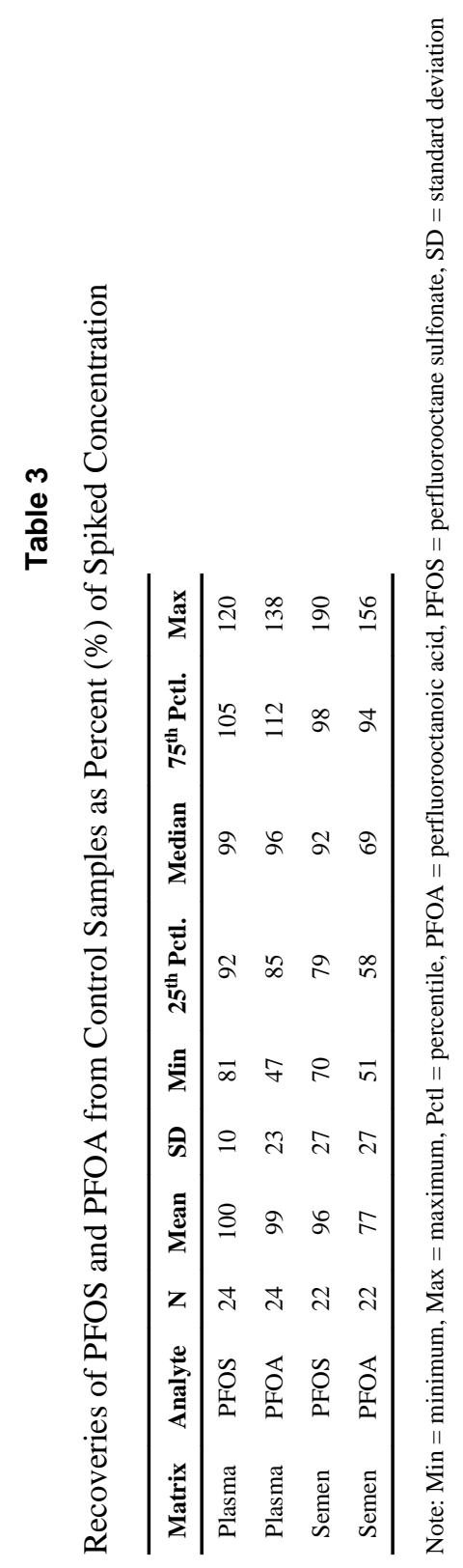

Reprod Toxicol. Author manuscript; available in PMC 2013 July 01. 


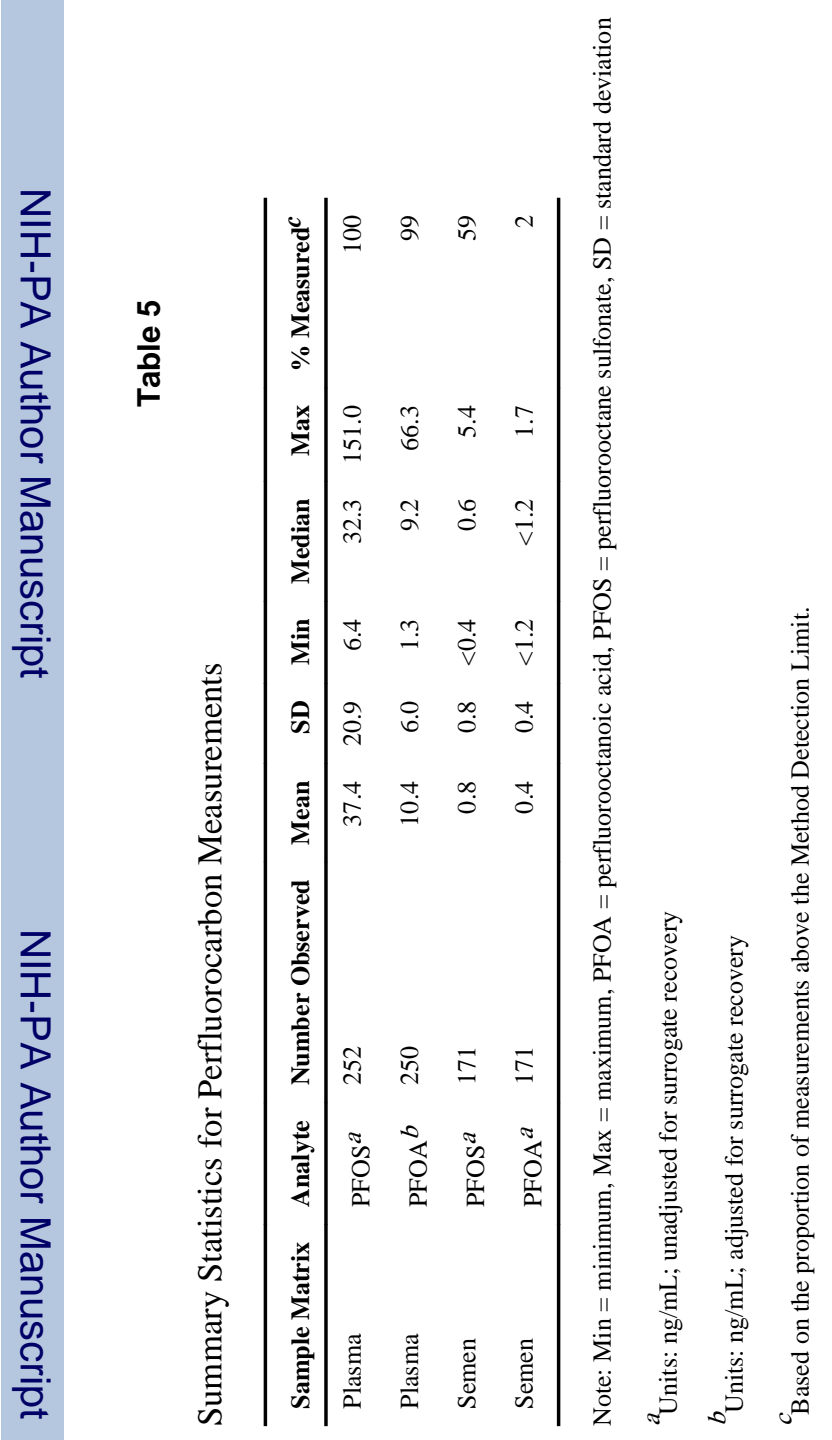

Reprod Toxicol. Author manuscript; available in PMC 2013 July 01. 


\begin{tabular}{|c|c|c|c|c|c|c|c|c|c|}
\hline$\sum_{\Sigma}^{\frac{x}{\pi}}$ & g & $\ddot{a}$ & $\mathscr{f}$ & ৪ & $\begin{array}{c}\ddagger \\
\infty\end{array}$ & \begin{tabular}{|c|}
$\infty$ \\
$\infty$ \\
$\infty$
\end{tabular} & $\pi$ & 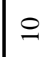 & $\stackrel{\circ}{\circ}$ \\
\hline$\Xi$ & $\bar{m}$ & $\ddot{~}$ & $\stackrel{i}{i}$ & $\bar{i}$ & \begin{tabular}{|l|} 
\\
0 \\
0 \\
0
\end{tabular} & 0 & $\bar{a}$ & $\because$ & $\approx$ \\
\hline 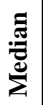 & $\therefore$ & $\hat{b}$ & $\hat{0}$ & \pm & $\exists$ & $\vec{i}$ & $\stackrel{\bullet}{+}$ & $\stackrel{2}{\stackrel{2}{2}}$ & $\exists$ \\
\hline के & \pm & $\stackrel{\leftrightarrow}{\oplus}$ & 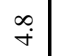 & $\stackrel{+}{+}$ & $\stackrel{m}{-}$ & $\stackrel{\sim}{\cong}$ & $\underset{i}{\infty}$ & 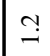 & $\stackrel{\circ}{\circ}$ \\
\hline$\frac{\sqrt{\varpi}}{\Sigma}$ & in & $\stackrel{\infty}{\sim}$ & $\begin{array}{c}\infty \\
\infty\end{array}$ & 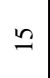 & $\stackrel{\sim}{\sim}$ & $\vec{i}$ & in & $\Rightarrow$ & $\cong$ \\
\hline $\mathrm{z}$ & $\tilde{\beth}$ & $\tilde{\widetilde{d}}$ & $\tilde{d}$ & 岕 & 芯 & $\overline{\mathfrak{s}}$ & $\stackrel{\mathscr{\lambda}}{\mathrm{d}}$ & బู & $\stackrel{\sim}{\sim}$ \\
\hline 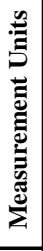 & $\begin{array}{l}\vec{\Xi} \\
\stackrel{\vec{g}}{2} \\
\stackrel{2}{2}\end{array}$ & $\begin{array}{l}\overrightarrow{g_{0}} \\
\stackrel{b}{\Rightarrow}\end{array}$ & 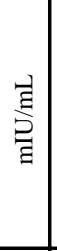 & $\begin{array}{l}\overrightarrow{\mathrm{g}} \\
\mathrm{o} \\
2\end{array}$ & 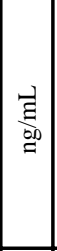 & 点 & \begin{tabular}{|l}
$\vec{\xi}$ \\
है \\
है
\end{tabular} & 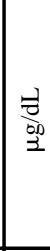 & $\stackrel{\vec{\theta}}{\frac{\partial}{\partial}}$ \\
\hline 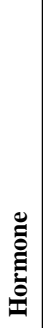 & 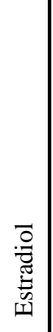 & $\begin{array}{l}\frac{\Xi}{0} \\
\frac{\pi}{0} \\
\frac{\pi}{2} \\
0\end{array}$ & 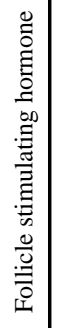 & 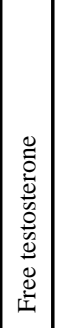 & 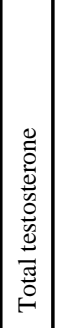 & 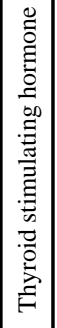 & 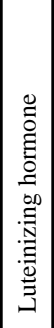 & 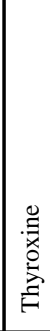 & 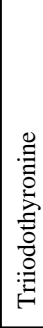 \\
\hline
\end{tabular}

Reprod Toxicol. Author manuscript; available in PMC 2013 July 01. 


\begin{tabular}{|c|c|c|c|c|c|c|c|c|c|c|c|c|c|c|c|c|c|c|c|c|c|c|c|c|c|}
\hline & 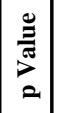 & & $\begin{array}{l}\vec{\jmath} \\
\stackrel{0}{0}\end{array}$ & $\hat{\tilde{\sigma}}$ & & & & & $\mid \begin{array}{l}\tilde{1} \\
\tilde{0} \\
0\end{array}$ & $\mid \begin{array}{l}\vec{\Xi} \\
\vdots \\
0\end{array}$ & & & & & $\mid \begin{array}{l}\tilde{m} \\
\mathfrak{f} \\
0\end{array}$ & $\mid \begin{array}{c} \pm \\
\vdots \\
0 \\
0\end{array}$ & & & & & $\mid \begin{array}{l}\hat{2} \\
\vdots \\
0\end{array}$ & $\left|\begin{array}{c}f \\
0 \\
0 \\
0\end{array}\right|$ & & & \\
\hline$\widehat{\mathrm{g}}$ & 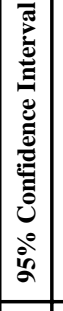 & & $\begin{array}{l}8 \\
0 \\
0 \\
0 \\
i \\
0 \\
0 \\
i \\
1\end{array}$ & 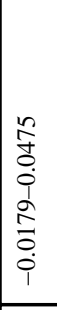 & & & & & 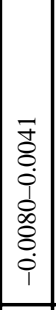 & 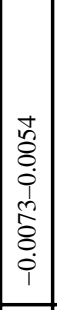 & & & & & $\begin{array}{c}0 \\
0 \\
i \\
i \\
i \\
0 \\
\hat{0} \\
i \\
1\end{array}$ & 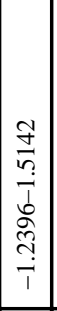 & & & & & 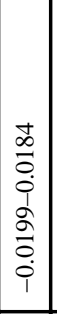 & $\begin{array}{ll}0 \\
0 \\
0 \\
0 \\
0 \\
0 \\
0 \\
0 \\
1\end{array}$ & & & \\
\hline 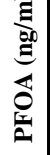 & 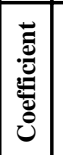 & & $\begin{array}{l}\infty \\
0 \\
0 \\
0\end{array}$ & 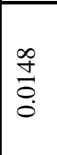 & & $\pi$ & $\pi$ & & 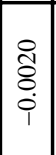 & $\left|\begin{array}{l}0 \\
0 \\
0 \\
i \\
1\end{array}\right|$ & & $\pi$ & $\pi$ & & 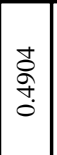 & $\begin{array}{c}\tilde{m} \\
\stackrel{0}{0}\end{array} \mid$ & & $\pi_{1}$ & 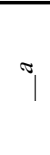 & & $\begin{array}{l}\hat{\vdots} \\
0 \\
0 \\
i\end{array}$ & $\begin{array}{l}0 \\
\vec{\partial} \\
0 \\
i\end{array}$ & & $\pi$ & $\pi$ \\
\hline & 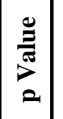 & & $\begin{array}{c}\text { t. } \\
\text { f. } \\
0\end{array}$ & $\vec{n}$ & & $\begin{array}{l}\infty \\
\vdots \\
0 \\
0\end{array}$ & $\bar{\sigma}$ & & $\mid \begin{array}{c}0 \\
\stackrel{0}{0} \\
\stackrel{0}{0}\end{array}$ & $\mid \begin{array}{c}\text { वे } \\
\stackrel{0}{0}\end{array}$ & & 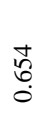 & $\begin{array}{l}\bar{m} \\
\text { on }\end{array}$ & & $\begin{array}{c} \pm \\
\dot{n} \\
0\end{array}$ & 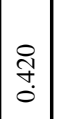 & & $\begin{array}{l}\text { Pे } \\
\text { f. }\end{array}$ & $\begin{array}{l}\text { స్త్రి } \\
0\end{array}$ & & $\mid$\begin{tabular}{l}
0 \\
\multirow{q}{q}{} \\
0 \\
0
\end{tabular} & $\mid \begin{array}{l}0 \\
f \\
f \\
0\end{array}$ & & 。ٕ. & $\mid$ \\
\hline & 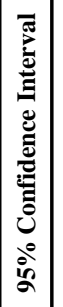 & & 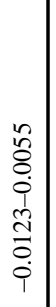 & 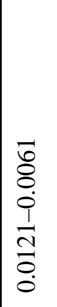 & & 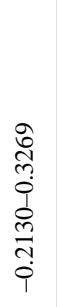 & 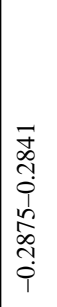 & & $\mid \begin{array}{c}0 \\
0 \\
0 \\
0 \\
0 \\
o \\
o \\
0 \\
i \\
i \\
1\end{array}$ & $\mid \begin{array}{c}1 \\
0 \\
0 \\
0 \\
0 \\
0 \\
0 \\
0 \\
0 \\
1 \\
1\end{array}$ & & 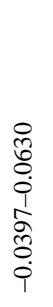 & 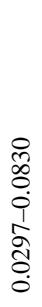 & & 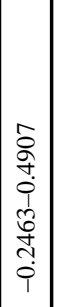 & 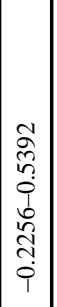 & & 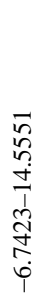 & 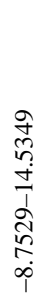 & & $\mid \begin{array}{c}0 \\
0 \\
0 \\
0 \\
1 \\
o \\
0 \\
0 \\
1 \\
1\end{array}$ & $\left|\begin{array}{c}0 \\
0 \\
0 \\
0 \\
1 \\
\hat{1} \\
0 \\
0 \\
1\end{array}\right|$ & & $\frac{\mathrm{d}}{\mathrm{m}}$ & 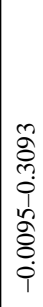 \\
\hline 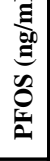 & 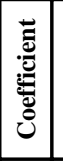 & & 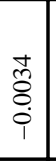 & $\begin{array}{l}0 \\
0 \\
0 \\
0 \\
1\end{array}$ & & $\begin{array}{l}0 \\
0 \\
0 \\
0 \\
0\end{array}$ & $\begin{array}{l}\frac{\pi}{0} \\
0 \\
0 \\
1 \\
\end{array}$ & & $\begin{array}{l}0 \\
\vdots \\
0 \\
0 \\
0\end{array}$ & \begin{tabular}{|l}
0 \\
$\vdots$ \\
0 \\
0
\end{tabular} & & $\begin{array}{l}= \\
\overline{0} \\
0 \\
i\end{array}$ & 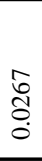 & & 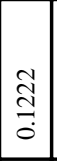 & $\begin{array}{l}\infty \\
0 \\
0 \\
0 \\
0\end{array}$ & & $\begin{array}{l}\text { 苗 } \\
\text { ले }\end{array}$ & $\begin{array}{l}\stackrel{0}{a} \\
\stackrel{\alpha}{i} \\
\text { i }\end{array}$ & & $\begin{array}{l}\tilde{1} \\
\delta \\
\vdots \\
i \\
\end{array}$ & $\begin{array}{l}0 \\
0 \\
0 \\
i \\
1\end{array}$ & & $\frac{d}{0}$ & 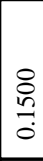 \\
\hline & $z$ & & $\stackrel{\infty}{\stackrel{\infty}{N}}$ & $\overline{\tilde{\lambda}}$ & & $\stackrel{8}{\circ}$ & $i$ & & 守 & $\vec{\lambda}$ & & 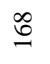 & n & & $\underset{\sim}{\text { f }}$ & $\underset{ন}{\not i}$ & & $\stackrel{\infty}{\sim}$ & $\stackrel{\circ}{n}$ & & ) & $\underset{\pi}{\sim}$ & & 8 & $i$ \\
\hline & & & 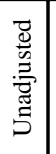 & $\begin{array}{l}\overrightarrow{0} \\
\vec{z} \\
\vec{z} \\
\vec{z}\end{array}$ & & 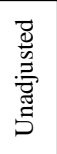 & $\begin{array}{l}\frac{z}{8} \\
\frac{8}{0} \\
\frac{3}{8} \\
\end{array}$ & & 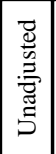 & 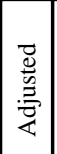 & & 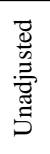 & 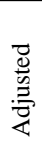 & & 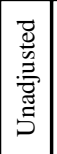 & 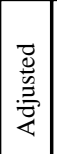 & & 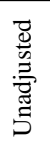 & 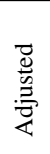 & & 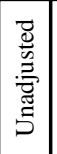 & 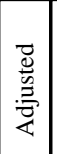 & & 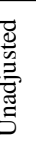 & 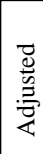 \\
\hline & & $\begin{array}{l}\frac{\pi}{5} \\
\frac{\pi}{2}\end{array}$ & & & 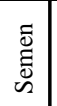 & & & 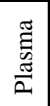 & & & \begin{tabular}{l|} 
\\
$\overline{0}$ \\
$\bar{D}$ \\
$\omega$
\end{tabular} & & & $\begin{array}{l} \\
\tilde{E} \\
\frac{\pi}{2} \\
\frac{\pi}{2}\end{array}$ & & & $\begin{array}{l} \\
\overline{0} \\
\bar{D} \\
\infty\end{array}$ & & & \begin{tabular}{|l|} 
\\
\\
$\frac{\pi}{\tilde{m}}$ \\
\multirow{2}{*}{}
\end{tabular} & & & 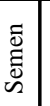 & & \\
\hline & 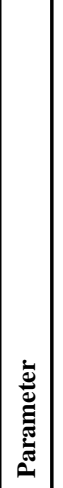 & 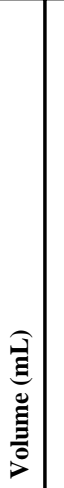 & & & & & & $\stackrel{ \pm}{2}$ & & & & & & 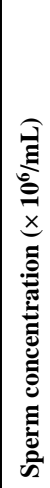 & & & & & & 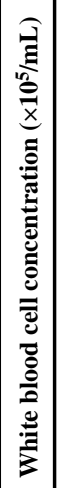 & & & & & \\
\hline
\end{tabular}




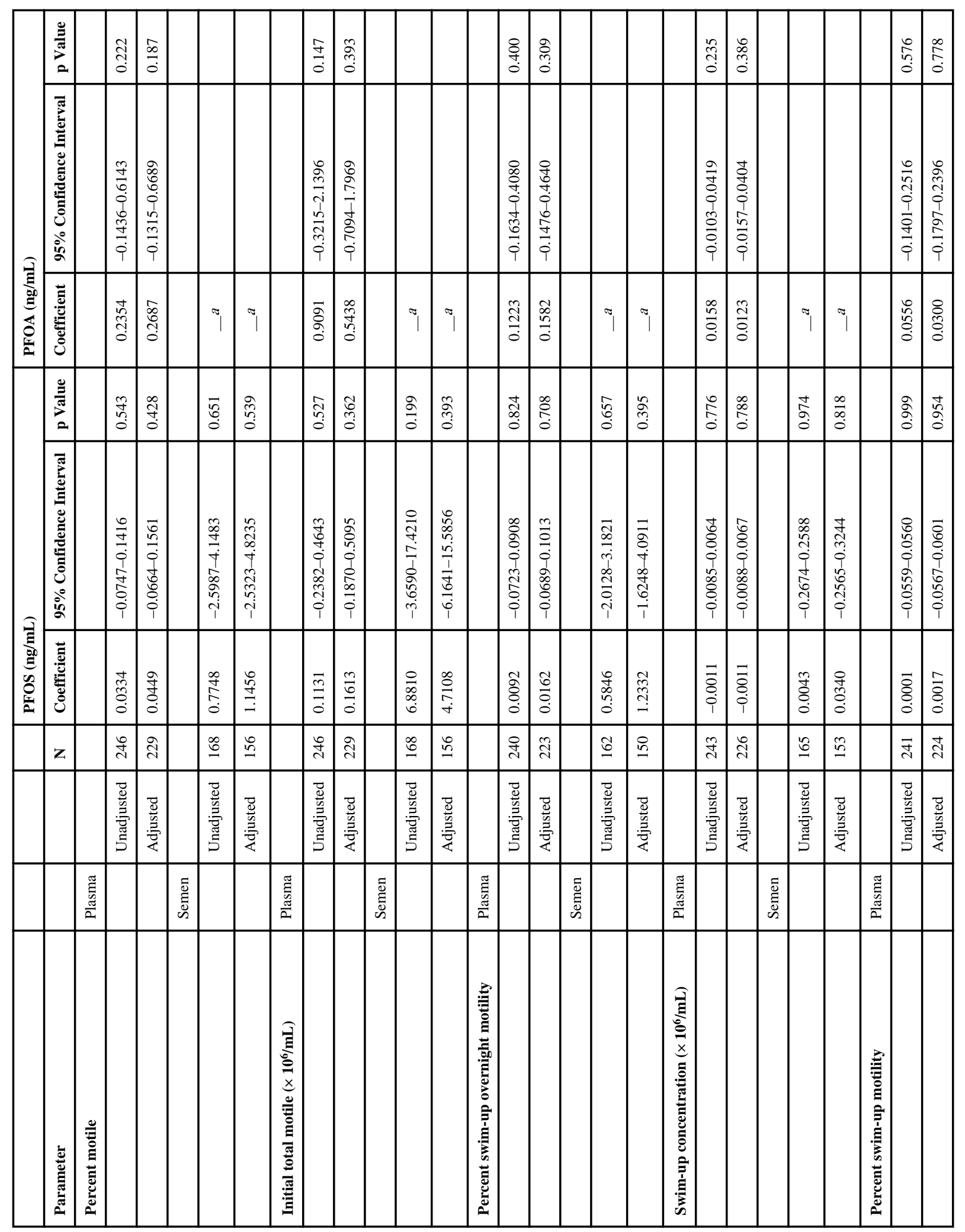




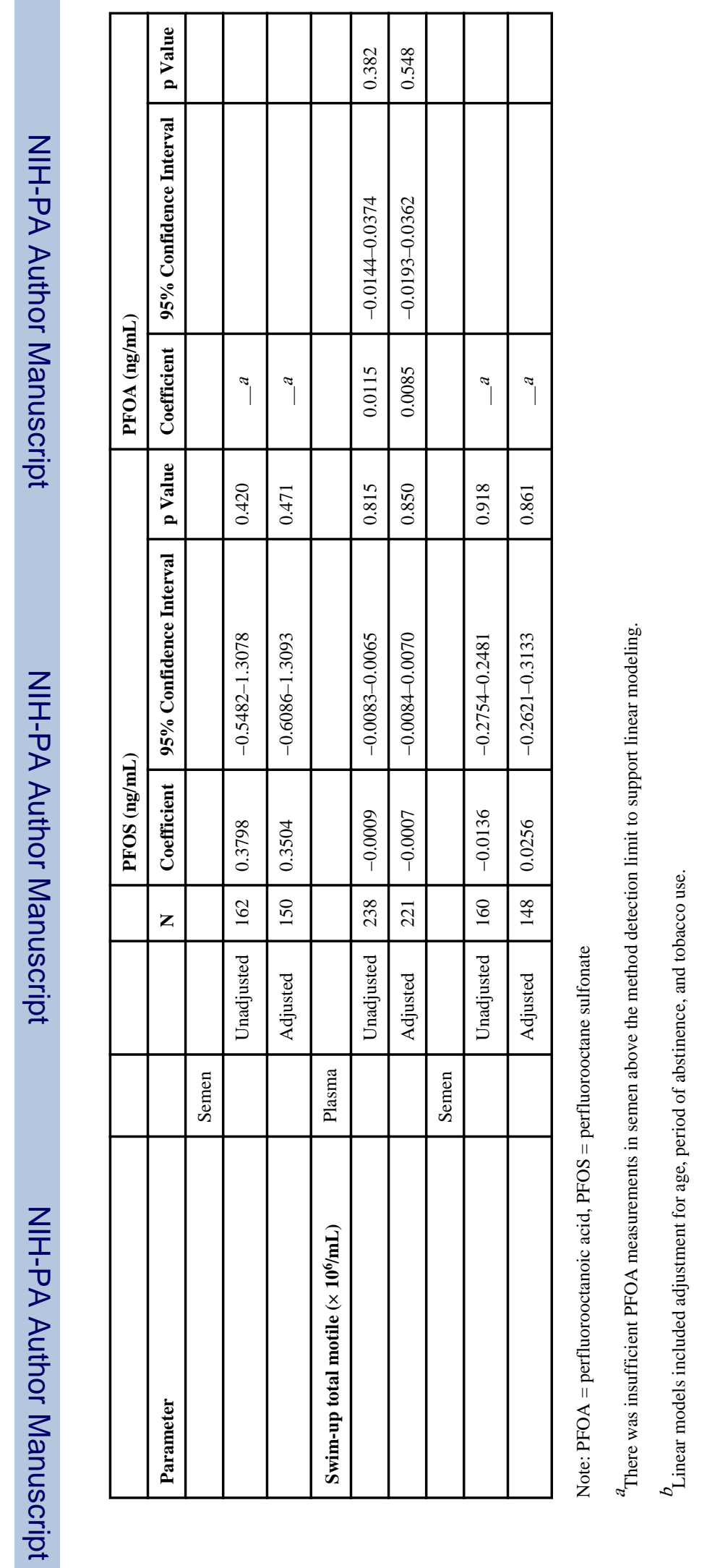

Reprod Toxicol. Author manuscript; available in PMC 2013 July 01. 


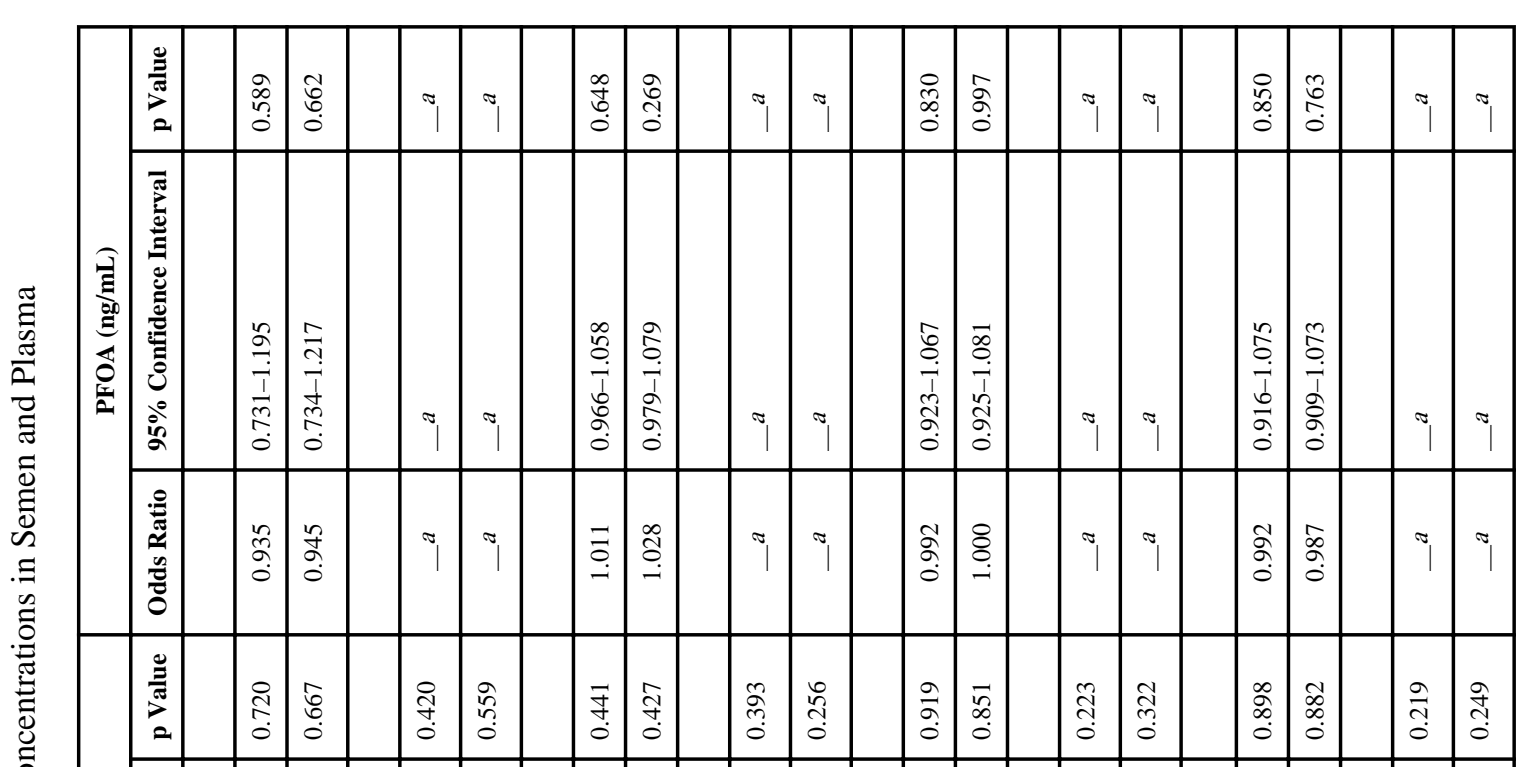

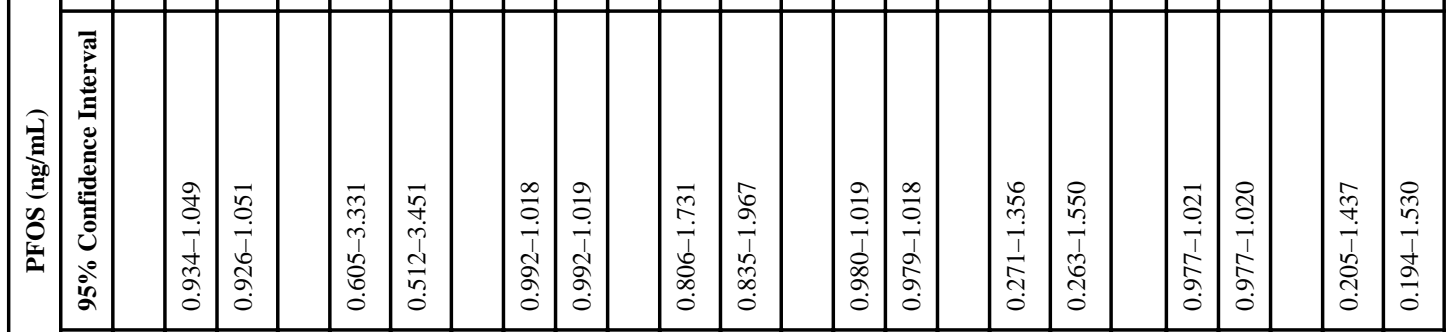

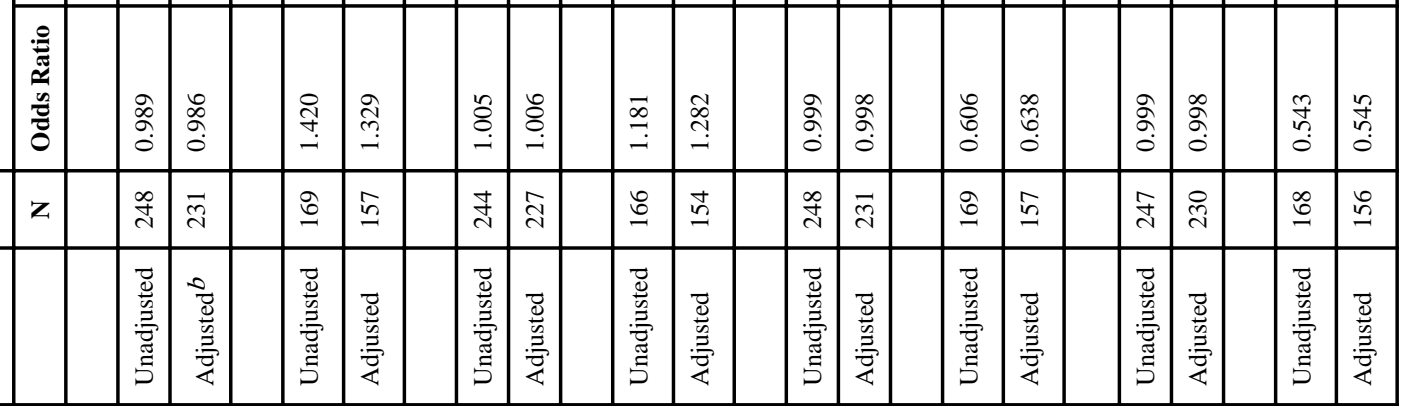

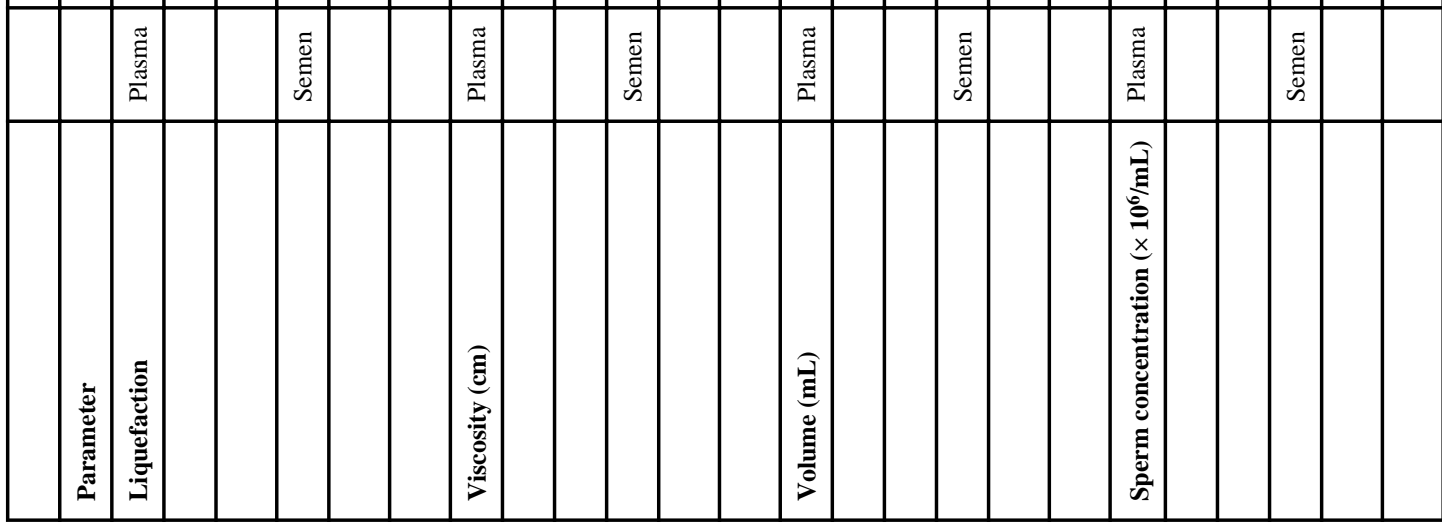




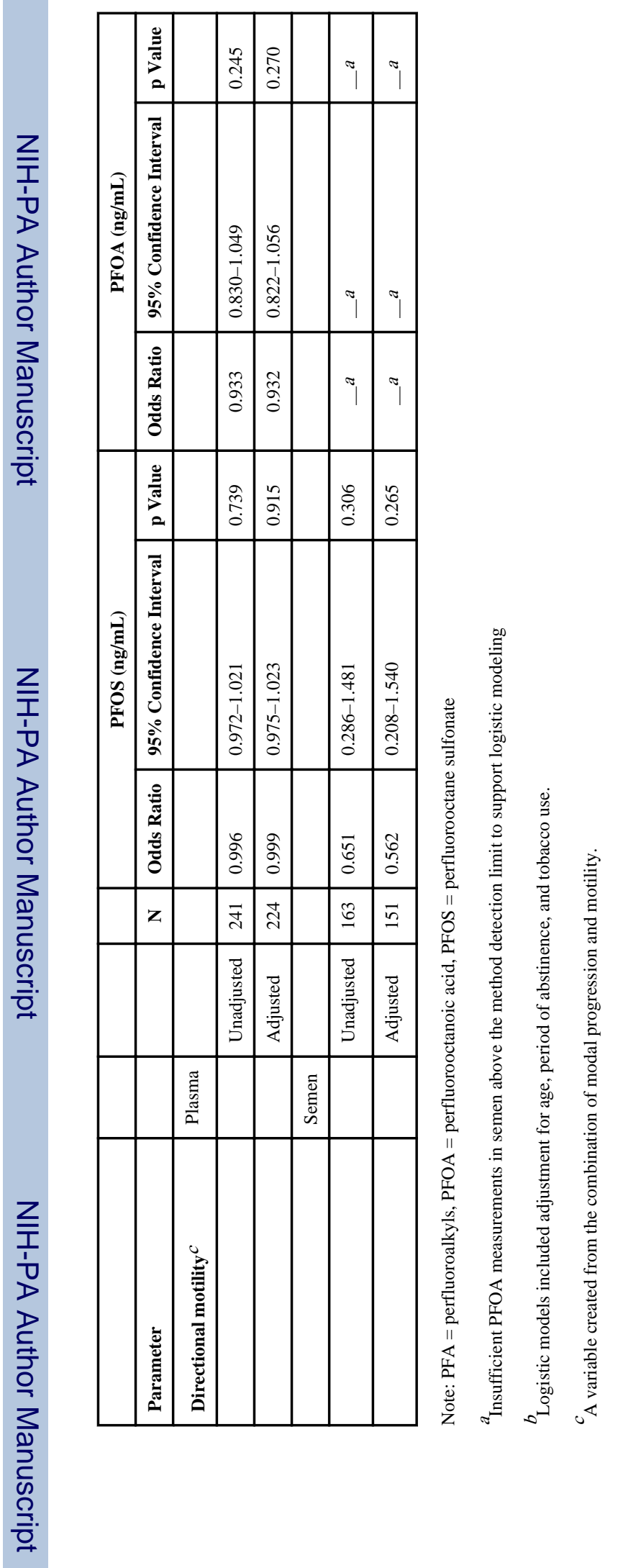

Reprod Toxicol. Author manuscript; available in PMC 2013 July 01. 


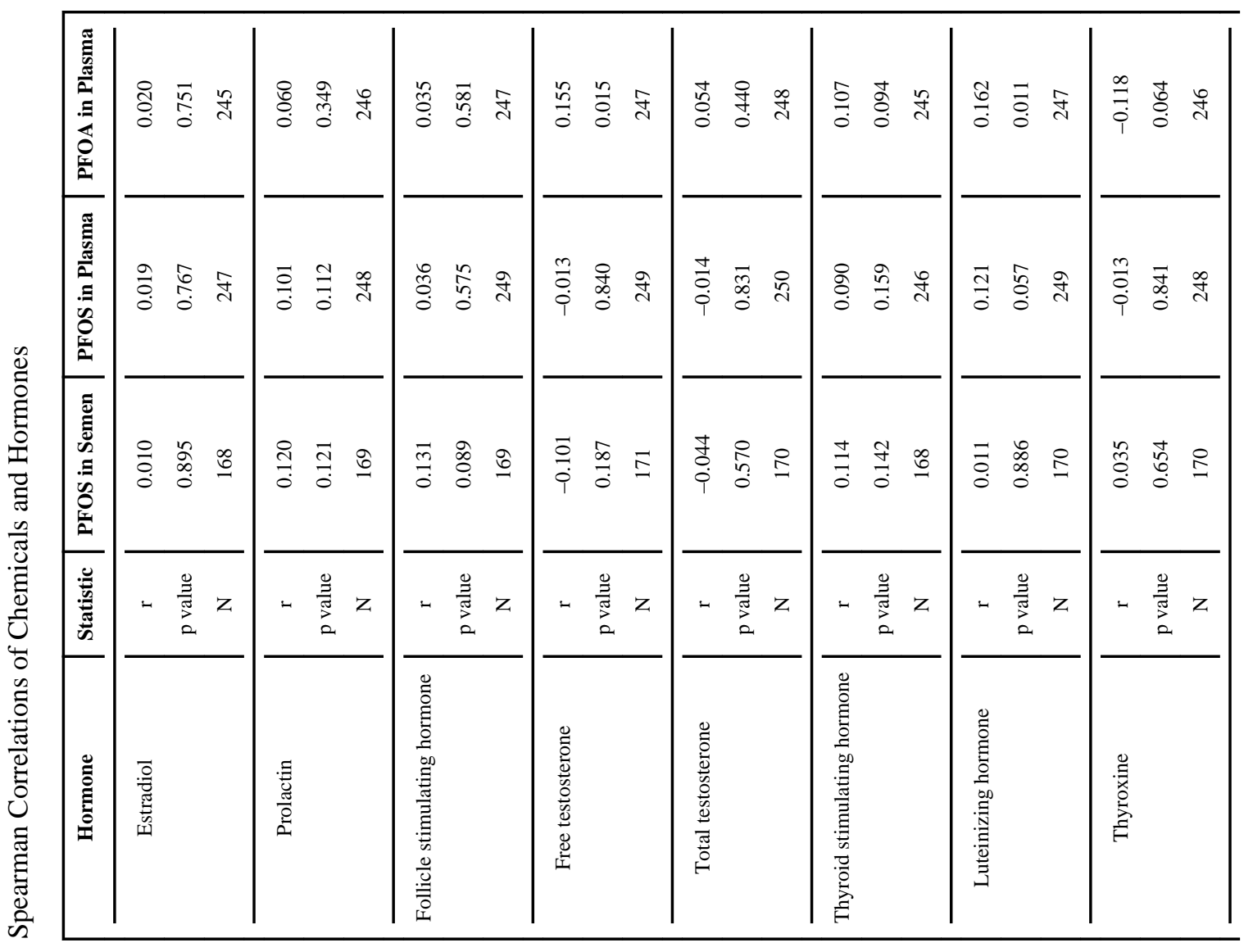




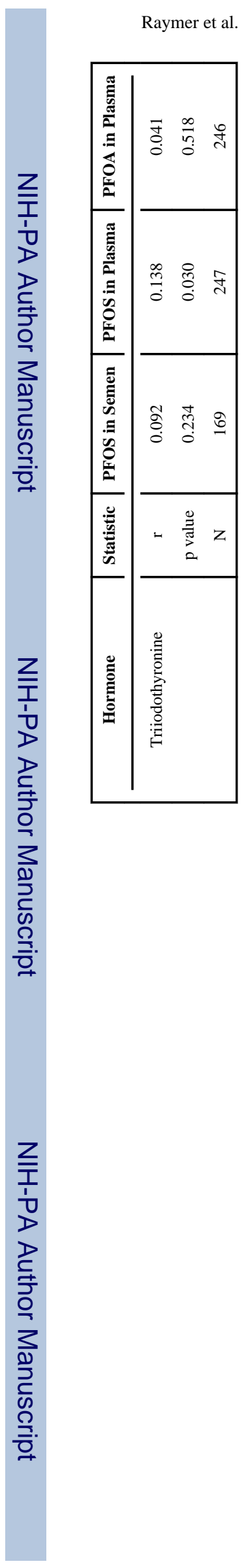

Page 25

Reprod Toxicol. Author manuscript; available in PMC 2013 July 01. 